\title{
Influencers On The Decision For Bariatric Surgery: A Pilot Study And Proposed Model
}

Elmer Ragus, M.B.A., University of Central Missouri, USA

Harry A Harmon, D.B.A., University of Central Missouri, USA

Craig A. Conrad, D.B.A., Western Illinois University, USA

\begin{abstract}
The costs associated with obesity in the United States are estimated to be $\$ 120$ billion annually and an estimated 400,000 deaths. In addition, obesity has been shown to significantly diminish the quality of life through lower self-esteem, depression, and discomfort in social situations. Although the treatment for obesity, defined as a body mass index (BMI) of 40, through bariatric surgery is not new, the literature is lacking in explaining the decision to undergo the procedure. The research reported here employs a small sample as a pilot study to examine potential influences on the decision-making process. Scales from the existing literature, e.g., vanity, fear of success, are adapted for this research. The findings suggest that prospective patients seek an enhanced quality of life but criticism by loved ones does not significantly influence the decision. The results suggest several issues that should be examined in greater detail with a larger sample.
\end{abstract}

Keywords: Weight Loss; Bariatric Surgery; Bypass Surgery; Obese; Obesity; BMI; Diabetes

\section{BACKGROUND}

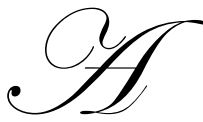

ccording to the U.S. Centers for Disease Control and Prevention (CDC), obesity is the top health risk facing the country. An individual is considered obese when his or her body weight is at least $30 \%$ over the ideal weight for a specified height. This measure usually coincides with a body mass index (BMI), a calculation that assesses weight relative to height, of more than 30 . Obesity occurs from the consumption of more calories than the body needs coupled with a sedentary lifestyle, and is exacerbated by a diet high in fat content. However, in addition to behavioral issues, obesity can also result from genetic determinations and hormonal problems. These factors explain why the process of achieving an ideal weight is more complex than monitoring caloric consumption and level of physical activity. (The Endocrine Society, 2009)

Obesity is a serious issue because it can be associated with an estimated 400,000 deaths per year in the United States and an economic cost over $\$ 120$ billion annually. These costs include medical treatment, workdays lost, restricted-activity days, and bed rest for overweight or obese people. In addition, obesity has been shown to significantly diminish the quality of life through lower self-esteem, depression, and discomfort in social situations. Serious health conditions include diabetes, heart disease, hypertension, metabolic syndrome, and reproductive issues. (The Endocrine Society, 2009) The following is a brief discussion of these issues and their treatment.

\section{Diabetes}

More than $80 \%$ of individuals with Type 2 diabetes are obese or overweight because obesity reduces insulin's ability to regulate blood sugar levels. Over time, this inability may lead to diabetes. Unfortunately, drug treatment is less effective for obese people because obesity increases insulin resistance and glucose intolerance. (The Endocrine Society, 2009)

\section{Heart Disease}


Obese people have an increased incidence of heart disease. The excessive body fat increases triglyceride levels and decreases high-density lipoprotein (HDL), i.e., "good cholesterol." Thus, an obese person is more likely to suffer from heart attacks, congestive heart failure, sudden cardiac death, angina, and abnormal heart rhythm than a healthy BMI individual. (The Endocrine Society, 2009)

\section{Hypertension}

Blood pressure, the force of blood pushing against the walls of arteries as the heart pumps out blood, rises as body weight increases. Therefore, obesity increases the risk of developing hypertension, or high blood pressure. Patients with hypertension are more likely to suffer from heart attacks, strokes, or kidney failures. (The Endocrine Society, 2009)

\section{Metabolic Syndrome}

Obesity impacts existing endocrine and metabolic disorders, a condition that affects one of every five overweight people, approximately $22 \%$ of the American population. This condition is characterized by a cluster of health problems including obesity, hypertension, abnormal lipid levels, and high blood sugar. Again the problems associated with diabetes, heart disease, or stroke. (The Endocrine Society, 2009)

\section{Reproductive Issues}

The majority of female patients diagnosed with polycystic ovary syndrome (PCOS) are either overweight or obese. PCOS is a leading cause of infertility in reproductive-age women and associated with insulin resistance. Thus, this condition increases the risk of developing diabetes. Obese men are also more likely to suffer from reproductive hormonal abnormalities, sexual dysfunction, and infertility. (The Endocrine Society, 2009)

\section{Treatment Option 1: Medication}

Prescription drug therapy may be incorporated into a patient's weight loss program when he or she has a BMI of more than 30 with no obesity-related conditions; or when the BMI is above 27 with two or more obesity related conditions. Medication may be effective for weight-loss when combined with lifestyle, behavioral, and dietary modifications. Long-term treatments include sympathomimetic drugs which inhibit one's appetite and lipase inhibitors which prevent enzymes from breaking down fat. Short-term treatments are for weight loss but are not used for patients with heart disease, high blood pressure, and thyroid conditions. Many over-the-counter pills are available for weight loss, although their efficacy has not been supported in any research studies. (The Endocrine Society, 2009)

\section{Treatment Option 2: Bariatric Surgery}

Bariatric surgery, also known as weight loss surgery, is the last option for weight loss when all other treatment regimes have failed. Obesity surgery is recommended only for patients with either a BMI of 40 or a BMI of 35 to 39.9 when coupled with other obesity-related medical conditions. Persons considering this surgery need to fully understand the risks, benefits, and lifestyle changes that accompany obesity surgery. A cadre of health care providers, e.g., general practitioners, endocrinologists, OB/GYNs, nutritionists, and psychologists, are made available to offer their expertise and guidance. Table 1 highlights characteristics exhibited by the more than 14,500 patients as compiled by the International Bariatric Surgery Registry. (The Endocrine Society, 2009)

In the laparoscopic bariatric surgery procedure, the surgeon uses a fiber-optic video camera and other specialized instruments through five or so one-inch openings through the abdomen. The high- definition quality of the video provides a better view of the procedure than is possible with the naked eye. Although there are different types of bariatric surgery, this study is focused on regular gastric bypass surgery, or roux-en-y gastric bypass. Figure 1 is an illustration of the procedure. The surgeon forms a small stomach pouch about the size of a golf ball. This pouch is separated from the bottom part of the stomach by completely dividing the stomach from itself. Any 
food consumed will now "bypass" the lower stomach and empty directly into the small intestine. The "bypassed stomach," with its digestive juices, will continue to empty in the uppermost small intestine. These two limbs eventually meet in a common limb at the small intestine where food is taken in by the walls of the common limb. Since these juices mix with food lower down in the intestines, less food and liquid is absorbed, and unabsorbed food is evacuated from the body. (Goldberg, Cowan, and Marcus, 2006)

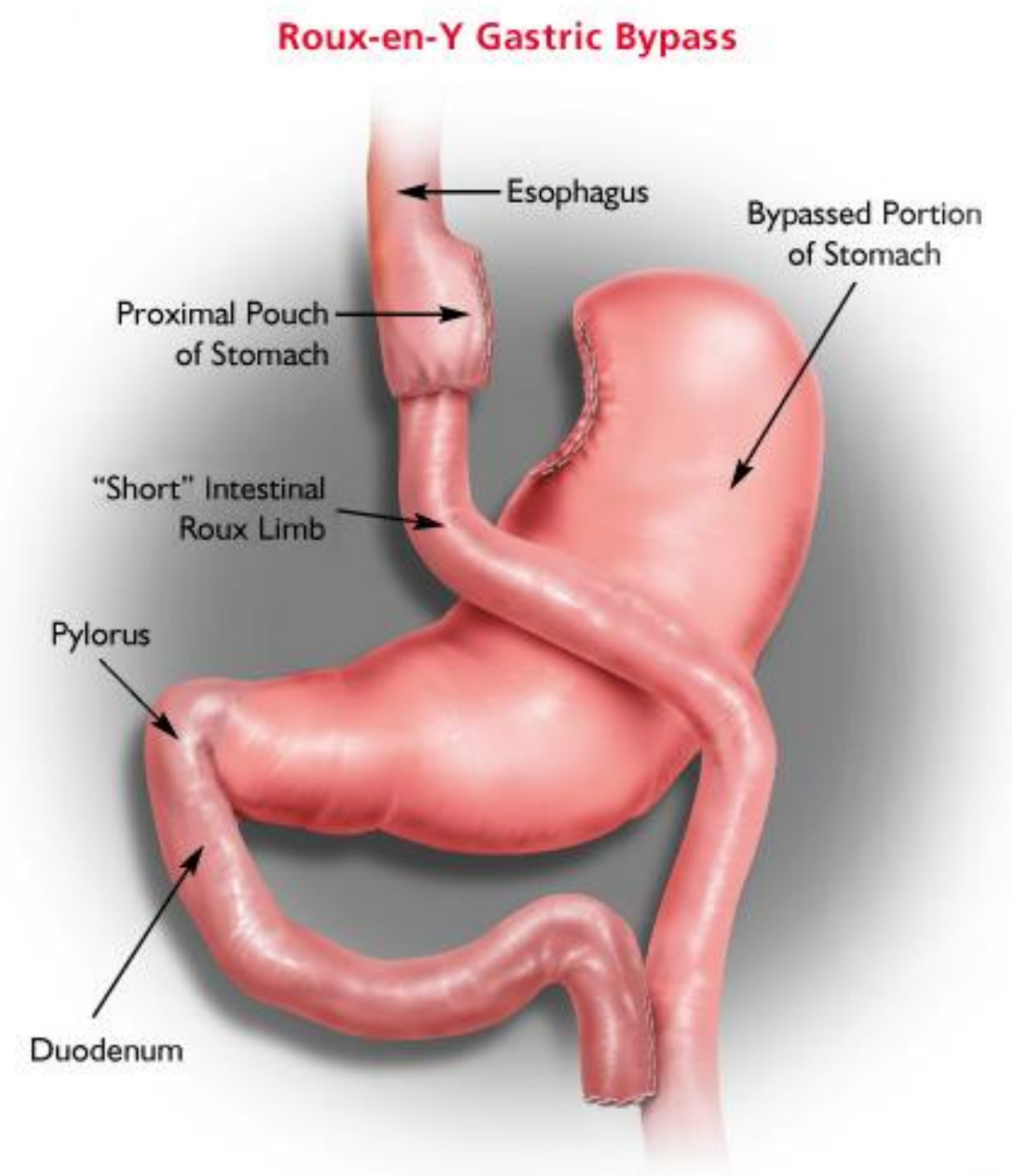

Figure 1: Roux-en-Y Gastric Bypass Illustration

As with any treatment options, bariatric surgery has benefits and risks. The most obvious benefit is rapid weight loss for 12 to 18 months following the surgery. The other is that patients may maintain $50 \%$ to $60 \%$ of their weight loss for 10 to 14 years after the surgery. An ancillary benefit is the improvement (reduction) of the several medical problems previously discussed, e.g., diabetes, hypertension, cardiac functioning, osteoarthritis, sleep apnea, stress incontinence, GERD, and cholesterol. (St. John's Health Systems, 2009) A study of 14,500 patients noted the following risks associated with the procedure:

- $1.35 \%$ required hospital stays lasting over a week due to complications involving the heart or liver, ruptured blood vessels in the lungs, infections in the diaphragm area, leaks in the stomach and intestine, blood clotting in the veins, and blockage of the small intestine.

- $5.28 \%$ required hospitals stays of less than seven days due to complications including difficulty breathing, 


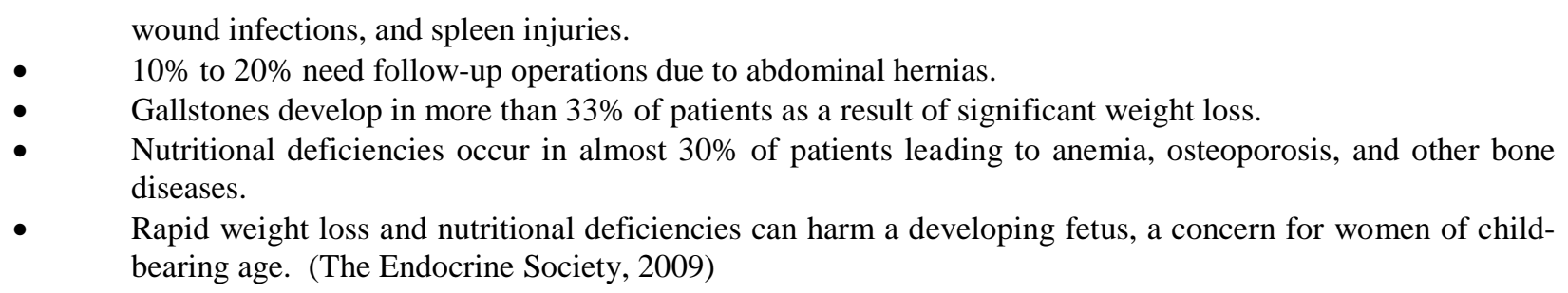

\section{RESEARCH QUESTION DEVELOPMENT}

The current study examines the different traits and conditions that influence a person to consider weight loss surgery. A better understanding of the individual's motivation is the study's objective and is worthwhile because the U.S. is the most overweight country in the world. A small sample pilot study is an appropriate method to test constructs and subsequently develop a more complete model. The common diet of junk food and the lack of exercise lead to the prediction that $75 \%$ of adults in the U.S. will be overweight by 2015 . Not surprisingly obesity will become the leading preventable cause of death in the United States. (Borland, 2007) Studies by American Sports Data (ASD) and the CDC indicate 133.6 million adults have a BMI over 25, and 63.6 million adults have a BMI above 30. (American Sports Data, 2006) This data indicates a need to better understand the obesity problem. A small sample pilot study is an appropriate method to test constructs and subsequently develop a more complete model.

\section{Related Literature}

We examine the issue of obesity and the psychosocial aspects that go with it. The study is also important because, although more and more people turn to bariatric surgery for weight loss, there are a few studies that consider the use of the Internet to inform the public about bariatric services. In Salant and Santry (2006) the authors argue that economic and professional motivations confuse patients. Existing websites may offer contradictory studies in that they insist upon genetics as the cause of obesity, yet point to individual behaviors in cases of surgery failures. However, few studies have conceptualized the barriers to weight loss and bariatric surgery. The study reported here differs in that it incorporates two possible motivations for weight loss. Specifically, the desire for enhanced relationships with loved ones and health consciousness are used to create a conceptual model that maps a prospective patient's decision-making process.

The information gathered from this study will aid in the understanding of the dynamics among the motivations and barriers to weight loss along with the underlying desire for a better quality of life. Unfortunately, the most formidable obstruction is a person's own psychology, e.g., he or she may find false comfort in resigning oneself to always being overweight or obese. Also, in a society that emphasizes unattainable standards of beauty, a person might be swayed by the paradoxes and criticisms presented by Hollywood. (Weightlossforall, 2009)

According to Thuan and Avignon (2005), the two biggest frustrations faced by health practitioners when assisting patients in weight loss treatments are poor compliance with the recommended program and lack of motivation tied to the setting of unrealistic goals. The most powerful factor to behavioral change to overcome such psychosocial barriers lies in the utilization of motivations for weight loss. The data collected will be useful to prospective bariatric surgery patients seeking a better quality of life for themselves and their loved ones.

The basic rationale is that people's quality of life is affected by relationship interferences and their loved ones' criticism of their weight. The framework models the consequences of changes in the quality of life. As this situation occurs, obese people are more likely to seek out weight-loss information including bariatric surgery option. Additionally, we examine certain behavioral characteristics impact on quality of personal relationships. Finally, we explore additional behavioral characteristics, i.e., fear of success, health consciousness, and vanity that affect the decision to undergo bariatric surgery. The proposed model is illustrated in the Appendix.

\section{Research Questions}


Gastric bypass is a means to an end. What people seek when they decide to do something about their obesity are the physical and nonphysical benefits that lead to a better quality of life. In one study, a group of women who underwent surgery improved their lives in five facets: physical function, physical role limitations, bodily pain, mental health, and general health. (Frezza, Shebani, and Wachtel, 2007) This leads to the following research question examined in the research reported here:

Research Question 1: People seek a better quality of life when they have a gastric bypass surgery.

Gastric bypass is a last resort to many obese patients. When other nonsurgical methods of weight loss have failed, bariatric surgery represents the best treatment for producing lasting weight loss in obese patients. As previously noted, the procedure is especially recommended for persons with BMIs above 35 and obesity-related ailments such as type 2 diabetes, sleep apnea, or heart disease. Surgery is not a universal remedy but can be highly effective for patients who are motivated to follow their physician's guidelines for nutrition, nutritional supplements, and exercise. (St. John's Health System, 2009) This leads to the following research question:

Research Question 2: Interest in gastric bypass and a high commitment to drastic changes in lifestyle are positively correlated.

\section{METHODOLOGY}

\section{Data Collection}

A survey methodology was employed for data collection to capture attitudes related to gastric bypass and obesity before surgery. A small sample $(\mathrm{n}=32)$ was collected from prospective patients considering bariatric surgery as a weight loss option at an informational meeting. After a lecture by a surgeon, interested persons were encouraged to seek additional information from surgery providers. The first step in the information process is a regularly scheduled informational seminar conducted by a local surgeon. During the session, the surgeon outlines the basics of obesity and gastric bypass including risks and benefits. Thereafter the necessary documents to begin the process are explained.

Before entering the classroom, people are provided a packet with various forms to complete, e.g., health history, patient information (demographics and insurance), and a medical release. Our data were collected by asking attendees to complete a survey along with the required paperwork. After two such informational seminars, a total of 32 completed questionnaires were received. Although the sample is small, we believe it to be adequate to develop a model for testing with a larger sample in the future.

\section{Measurement Instrument}

The survey has 73 questions/items developed from 13 different scales using the 1-to5 Likert response scale that is anchored with " 1 " = strongly disagree, and " 5 " = strongly agree. The thirteen different scales cover selfblame, future despair, depression, relationship interference, loved ones' criticism of weight, health care provider caring behavior, health care provider choice, quality of life, health consciousness, vanity, fear of success, bariatric surgery considerations, and information gathering. The first eight scales were adapted from The Chronic Pain Care Workbook by Michael J. Lewandowski. The ninth scale is from "Consumer Attitudes toward Health and Health Care: A Differential Perspective" by Stephen J. Gould. The tenth scale is from "Trait Aspects of Vanity: Measurement and Relevance to Consumer Behavior" by Richard G. Netemeyer, Scot Burton, and Donald R. Lichtenstein. The eleventh scale is from "An Objective Measure of Fear of Success: Construction and Validation" by M. Zuckerman and S.N. Allison. All of these scales in their original and complete format have been used successfully as reported in the literature. The last two scales are original questions developed for this research. The questionnaire also included demographic information. The questionnaire is provided in the Appendix.

\section{Measure Development}


The data were edited including the several reverse coded items and SPSS was used to analyze the data.

\section{RESULTS}

Table 1

Sample Characteristics

\begin{tabular}{|l|c|}
\hline \multicolumn{1}{|c|}{ Criteria } & Statistic \\
\hline Average Age & 47 \\
\hline Age Range & 20 to 72 \\
\hline Married & $59.4 \%$ \\
\hline Average Number of Children & 2.1 \\
\hline Caucasian & $93.8 \%$ \\
\hline Some College Courses & $59.4 \%$ \\
\hline Two and Four-year Degree & $37.6 \%$ \\
\hline Some Graduate Work & $3 \%(1$ patient) \\
\hline Do Not Work Outside Home & $59.4 \%$ \\
\hline
\end{tabular}

Table 2

Scales Means

\begin{tabular}{|l|c|c|}
\hline \multicolumn{1}{|c|}{ Scale } & Mean & Standard Deviation \\
\hline Self Blame & 3.1607 & .48649 \\
\hline Future Despair & 3.5687 & .63674 \\
\hline Depression & 3.1979 & .85450 \\
\hline Relationship Interference & 2.7969 & .99482 \\
\hline Partner Criticism & 2.2396 & .1677 \\
\hline Quality of Life & 3.4744 & .33916 \\
\hline Consideration & 2.8125 & .97227 \\
\hline Information & 3.6719 & .36194 \\
\hline Fear of Success & 3.2478 & .66866 \\
\hline Health Consciousness & 4.1615 & .69810 \\
\hline Vanity & 3.8438 & .61067 \\
\hline Provider Caring & 4.0078 & .72813 \\
\hline Physician Choice & 3.3047 & \\
\hline
\end{tabular}

Sample $=32$

Table 3

Marital Status

\begin{tabular}{|l|c|c|c|}
\hline \multicolumn{1}{|c|}{ Status } & Frequency & Percent & Cumulative Percent \\
\hline Divorced & 4 & 12.5 & 12.5 \\
\hline Married & 19 & 59.4 & 71.9 \\
\hline Single & 6 & 18.8 & 90.6 \\
\hline Separated & 1 & 3.1 & 93.8 \\
\hline Widowed & 2 & 6.2 & 100 \\
\hline
\end{tabular}

Sample $=32$

Table 4

Gender

\begin{tabular}{|l|c|c|c|}
\hline & Frequency & Percent & Cumulative Percent \\
\hline Male & 7 & 21.9 & 21.9 \\
\hline Female & 25 & 78.1 & 100.0 \\
\hline Total & 32 & 100.0 & \\
\hline
\end{tabular}

Table 5 


\begin{tabular}{|c|c|c|c|}
\hline \multicolumn{2}{|c|}{ Age } & Cumulative Percent \\
\hline Level & Frequency & 9.4 & 9.4 \\
\hline $20 \mathrm{~s}$ & 2 & 21.8 & 31.2 \\
\hline $30 \mathrm{~s}$ & 7 & 31.3 & 62.5 \\
\hline $40 \mathrm{~s}$ & 10 & 15.6 & 78.1 \\
\hline $50 \mathrm{~s}$ & 5 & 18.8 & 96.9 \\
\hline $60 \mathrm{~s}$ & 6 & 3.1 & 100.0 \\
\hline $70 \mathrm{~s}$ & 1 & 100.0 & \\
\hline
\end{tabular}

Table 6

Education

\begin{tabular}{|c|c|c|c|}
\hline Level Completed & Frequency & Percent & Cumulative Percent \\
\hline 11 & 1 & 3.1 & 3.1 \\
\hline 12 & 11 & 34.4 & 37.5 \\
\hline 13 & 4 & 12.5 & 50 \\
\hline 14 & 6 & 18.8 & 68.8 \\
\hline 15 & 2 & 6.2 & 75.0 \\
\hline 16 & 6 & 18.8 & 93.8 \\
\hline 17 & 1 & 3.1 & 96.9 \\
\hline 18 & 1 & 3.1 & 100 \\
\hline
\end{tabular}

Table 7

Work Outside Home

\begin{tabular}{|l|c|c|c|}
\hline & Frequency & Percent & Cumulative Percent \\
\hline No & 19 & 59.4 & 59.4 \\
\hline Yes & 13 & 40.6 & 100 \\
\hline Total & 32 & & \\
\hline
\end{tabular}

Table 8

Children

\begin{tabular}{|l|c|c|c|}
\hline & Frequency & Percent & Cumulative Percent \\
\hline $\mathbf{0}$ & 4 & 12.5 & 12.5 \\
\hline $\mathbf{1}$ & 3 & 9.4 & 21.9 \\
\hline $\mathbf{2}$ & 12 & 37.5 & 59.4 \\
\hline $\mathbf{4}$ & 11 & 34.4 & 93.8 \\
\hline Total & 2 & 6.2 & 100 \\
\hline
\end{tabular}

Table 9

\begin{tabular}{|l|c|}
\hline Number of Bariatric Surgery Patients & 14500 \\
\hline Average Weight at Time of Operation & 279.4 pounds \\
\hline Average BMI & 46 \\
\hline Patients with BMI between 35 and 39.9 & $19.7 \%$ \\
\hline Patients with BMI 40 and above & $76.1 \%$ \\
\hline
\end{tabular}

Source: International Bariatric Surgery Registry 
Correlations

\begin{tabular}{|c|c|c|c|c|c|c|c|c|c|c|c|}
\hline & & $\begin{array}{l}\text { Quality } \\
\text { Of Life } \\
\end{array}$ & $\begin{array}{l}\text { Future } \\
\text { Despair }\end{array}$ & Depression & $\begin{array}{l}\text { Relationship } \\
\text { Interference }\end{array}$ & $\begin{array}{c}\text { Partner } \\
\text { Criticism }\end{array}$ & Consideration & $\begin{array}{l}\text { Fear Of } \\
\text { Success }\end{array}$ & $\begin{array}{c}\text { Health } \\
\text { Consciousness }\end{array}$ & $\begin{array}{c}\text { Provider } \\
\text { Caring }\end{array}$ & $\begin{array}{c}\text { Physician } \\
\text { Choice }\end{array}$ \\
\hline \multirow[t]{2}{*}{ Quality Of Life } & \multirow{2}{*}{$\begin{array}{l}\text { Pearson Correlation } \\
\text { Sig. (2-tailed) }\end{array}$} & 1.000 & .177 & -.334 & -.281 & $-.442^{*}$ & .239 & .215 & $.401^{*}$ & -.178 & .193 \\
\hline & & & .333 & .061 & .119 & .011 & .187 & .238 & .023 & .330 & .290 \\
\hline \multirow[t]{2}{*}{ Future Despair } & \multirow{2}{*}{$\begin{array}{l}\text { Pearson Correlation } \\
\text { Sig. (2-tailed) }\end{array}$} & .177 & 1.000 & -.206 & .076 & .224 & -.049 & $.517^{* *}$ & .055 & .009 & .202 \\
\hline & & .333 & & .259 & .678 & .217 & .791 & .002 & .764 & .961 & .267 \\
\hline \multirow[t]{2}{*}{ Depression } & \multirow{2}{*}{$\begin{array}{l}\text { Pearson Correlation } \\
\text { Sig. (2-tailed) }\end{array}$} & -.334 & -.206 & 1.000 & $.384^{*}$ & $.526^{* *}$ & -.140 & -.176 & -.258 & $.373^{*}$ & .051 \\
\hline & & .061 & .259 & & .030 & .002 & .446 & .335 & .153 & .035 & .781 \\
\hline \multirow{2}{*}{$\begin{array}{l}\text { Relationship } \\
\text { Interference }\end{array}$} & \multirow{2}{*}{$\begin{array}{l}\text { Pearson Correlation } \\
\text { Sig. (2-tailed) }\end{array}$} & -.281 & .076 & $.384^{*}$ & 1.000 & $.659^{* *}$ & -.191 & .093 & -.084 & .169 & .061 \\
\hline & & .119 & .678 & .030 & & .000 & .295 & .612 & .646 & .356 & .741 \\
\hline \multirow[t]{2}{*}{ Partner Criticism } & \multirow{2}{*}{$\begin{array}{l}\text { Pearson Correlation } \\
\text { Sig. (2-tailed) }\end{array}$} & $-.442^{*}$ & .224 & $.526^{* *}$ & $.659^{* *}$ & 1.000 & $-.356^{*}$ & .124 & -.141 & .235 & .014 \\
\hline & & .011 & .217 & .002 & .000 & & .045 & .499 & .443 & .196 & .938 \\
\hline \multirow[t]{2}{*}{ Consideration } & \multirow{2}{*}{$\begin{array}{l}\text { Pearson Correlation } \\
\text { Sig. (2-tailed) }\end{array}$} & .239 & -.049 & -.140 & -.191 & $-.356^{*}$ & 1.000 & -.277 & .200 & -.246 & .158 \\
\hline & & .187 & .791 & .446 & .295 & .045 & & .124 & .272 & .175 & .389 \\
\hline \multirow[t]{2}{*}{ Fear Of Success } & \multirow{2}{*}{$\begin{array}{l}\text { Pearson Correlation } \\
\text { Sig. (2-tailed) }\end{array}$} & .215 & $.517^{* *}$ & -.176 & .093 & .124 & -.277 & 1.000 & .264 & .022 & $.438^{*}$ \\
\hline & & .238 & .002 & .335 & .612 & .499 & .124 & & .144 & .904 & .012 \\
\hline \multirow{2}{*}{$\begin{array}{l}\text { Health } \\
\text { Consciousness }\end{array}$} & \multirow{2}{*}{$\begin{array}{l}\text { Pearson Correlation } \\
\text { Sig. (2-tailed) }\end{array}$} & $.401^{*}$ & .055 & -.258 & -.084 & -.141 & .200 & .264 & 1.000 & -.299 & .124 \\
\hline & & .023 & .764 & .153 & .646 & .443 & .272 & .144 & & .096 & .500 \\
\hline \multirow[t]{2}{*}{ Provider Caring } & \multirow{2}{*}{$\begin{array}{l}\text { Pearson Correlation } \\
\text { Sig. (2-tailed) }\end{array}$} & -.178 & .009 & $.373^{*}$ & .169 & .235 & -.246 & .022 & -.299 & 1.000 & .212 \\
\hline & & .330 & .961 & .035 & .356 & .196 & .175 & .904 & .096 & & .244 \\
\hline \multirow[t]{2}{*}{ Physician Choice } & \multirow{2}{*}{$\begin{array}{l}\text { Pearson Correlation } \\
\text { Sig. (2-tailed) }\end{array}$} & .193 & .202 & .051 & -.061 & -.014 & -.158 & $.438^{*}$ & -.124 & .212 & 1.000 \\
\hline & & .290 & .267 & .781 & .741 & .938 & .389 & .012 & .500 & .244 & \\
\hline
\end{tabular}

*Significant at 0.05 level ** Significant at 0.01 level 
Based on the identified significant correlations, the conceptual model was revised to better reflect the study's findings. (Figure 2, Appendix.) Self-blame and future despair do not affect relationship interference while depression and loved ones' criticism of weight have a positive correlation with relationship interference. Relationship interference does not affect quality of life. However, loved ones' criticism of weight has a negative correlation with quality of life along with bariatric surgery consideration. Quality of life, information gathering, and vanity do not influence the decision as proposed in the origin model. However, depression does have a positive correlation with health care provider caring behavior. Also, future despair has a positive correlation with fear of success which in turn has a positive correlation with health care provider choice.

\section{DISCUSSION}

A majority of the prospective bariatric patients are female, married, have two or three children, have attended college, and do not work outside the home. They generally have a formal education so as to have an understanding of the qualifications, risks, and benefits that go with bariatric surgery to treat their obesity and obesity-related health issues. However, despite their qualifications and average age, they may be unable to take on any meaningful type of employment outside the home. As the mean quality of life score (3.47) indicates, respondents do not necessarily agree that their weight negatively impacts their life situation. The relatively low fear of success mean would suggest a similar conclusion. The results suggest the decision for bariatric surgery cannot be explained by relationship interference (mean 2.796), partner criticism (mean 2.24) or depression issues (mean 3.20) on average. The results suggest the respondents expect the health care providers to be sensitive to their needs (mean 4.01). Also, respondents exhibit a high degree of health consciousness (mean 4.16). Therefore, Research Questions 1 and 2 are answered in the affirmative. Prospective bariatric patients are searching to improve their quality of life due to their increased awareness of their health. The person considering the procedure acknowledges obesity is a problem, and actively seeks solutions. Also, greater health consciousness indicates that the prospective patient is willing to commit to changes in his or her lifestyle.

The relationships between future despair and fear of success also provides insight into health care provider choice. Future despair is positively correlated to fear of success which is, in turn, positively correlated to health care provider choice. The respondents, on average have a future despair score of 3.57.

The results (mean 3.67) indicate prospective bariatric patients gather information over the Internet and their general practitioners regarding bariatric surgery. Much of the information available about obesity and its problems suggest that surgery may be the last and only option to curing or to improving their obesity-related ailments. However the respondents in this study indicate that they do not necessarily suffer from relationship problems and they are supported by their loved ones to undergo surgery. They expect their health care providers to understand their need to have a trusting and caring relationship. The results suggest the need or desire to improve the quality of life, or to maintain their quality of life, to be a primary factor in the decision making process.

Future despair is positively correlated to fear of success and provider choice. Those relationships suggest prospective patients seek information about the surgeon's qualifications and success rates, mean of 3.67 on the information gathering scale. Recall that prospective patients may find contradictory information on current web sites. This research indicates that a web site should contain the usual information, e.g., gastric bypass, obesity, and diseases information, and also emphasize the improvements in personal relationships that may result. For example, successful bariatric patients can share stories about how losing weight helped them be able to "chase their grandchildren around the front yard" without any problems. Patients want to go to health care providers who indicate they care so the web site might highlight any philanthropic activities. Finally, prospective patients, on average, scored high on the vanity scale (4.16). Therefore, the web site should include before and after pictures to further motivate people to consider the surgery and its benefits.

\section{CONCLUSION}

This study adds to the growing body of literature that addresses obesity in this country. Obesity and obesity-related illnesses are a very real problem for a significant portion of the adult population and is a problem that is expected to continue to increase. The conceptual model offered in this study could aid family members and health 
care providers in their appreciation and understanding of the underlying motivations that drive prospective bariatric patients.

\section{LIMITATIONS}

This study is subject to several limitations. First, the sample size of 32 is fairly small. The conceptual model can be further improved by increasing the sample size which would also aid in validating the measurement scale issues. Second, the questionnaire only focused on thirteen qualities. There may be other characteristics that correlate with quality of life and bariatric surgery consideration. Third, it focused on correlations among the thirteen scales measured. Other significant correlations may exist with some of the demographic information gathered that are less apparent (and meaningful) with the small sample. For example, a higher degree of health consciousness may be positively correlated to age. Fourth, the questionnaire developed is for people who probably have taken a first step and are considering their options. Future research might examine past prospective patients who decided not to undergo treatment, as well as those who did have the surgery.

\section{AUTHOR INFORMATION}

Elmer Ragus is a Creative Associate at Callis \& Associates, a digital marketing agency. He received the M.B.A. with an emphasis in marketing from the University of Central Missouri. He is an adjunct instructor at National American University. He has extensive experience in the printing industry and an academic background in economics, business administration and marketing. His teaching and writing are focused in management, marketing, social media, and technology. E-mail: e.ragus@ sbcglobal.net

Harry A. Harmon is Professor of Marketing at University of Central Missouri, and the 2008 Distinguished Professor for the College of Business. He received the D.B.A. from Louisiana Tech University. He is published in Journal of Business \& Industrial Marketing, Psychology and Marketing, Journal of Marketing Communications, International Business \& Economics Research Journal, Marketing Intelligence and Planning, Journal of Marketing Theory \& Practice, other journals and various national proceedings. E-mail: HARMON@ucmo.edu

Craig A. Conrad is Associate Professor of Marketing at Western Illinois University. He received the D.B.A. from Louisiana Tech University. He does extensive consulting with varied firms both national and local developing strategies and responses to opportunities. He is published in Journal of Business \& Industrial Marketing, Psychology and Marketing, Journal of Business and Behavioral Studies, other journals and various national proceedings. E-mail: ca-conrad1@wiu.edu

\section{REFERENCES}

1. American Sports Data. "ASD \& CDC Research Statistics on Obesity in the United States." 2006. American Sports Data, Inc. 20 Apr. 2009. 〈http://www.americansportsdata.com/obesityresearch.asp >.

2. $\quad$ Borland, Sophie. "Obese America: 75pc Overweight by 2015." 2007. Telegraph.Co.Uk. 20 Apr. 2009. < http://www.telegraph.co.uk/news/worldnews/1557923/Obese-America-75pc- overweight-by-2015.html>.

3. $\quad$ Frezza, Eldo E., Shebani, Khaled O., and Wachtel, Mitchell S. "Laparoscopic Gastric Bypass for Morbid Obesity Decreases Bodily Pain, Improves Physical Functioning, and Mental and General Health in Women.” Journal of Laparoendoscopic \& Advanced Surgical Techniques. 17.4 ( 2007): 440-447 .

4. Goldberg, Merle Cantor, Cowan, Jr., George, and Marcus, William Y. Weight Loss Surgery: Is It Right for You? Garden City Park: Square One Publishers, 2006.

5. Gould, Stephen J. "Consumer Attitudes Toward Health and Health Care: A Differential Perspective." Journal of Consumer Affairs, 22 (1988): 96-118.

6. Lewandowski, Michael J. The Chronic Pain Care Workbook. Oakland: New Harbinger Publications, Inc., 2006.

7. Netemeyer, Richard G., Burton, Scot, and Lichtenstein, Donald R. "Trait Aspects of Vanity: Measurement and Relevance to Consumer Behavior.” Journal of Consumer Research, 21 (1995): 612626. 
8. $\quad$ St. John's Mercy. "Why Surgery?” 2009. St. John’s Health System. 20 Apr. 2009 〈http://www.stjohns.com/Bariatrics/whysurgery.aspx $>$.

9. Salant, Talya, and Santry, Heena P. "Internet Marketing of Bariatric Surgery: Contemporary Trends in the Medicalization of Obesity." Social Science \& Medicine, 62.10 (2006): 2445-2457.

10. Thuan, J-F, and Avignon, A. "Obesity Management: Attitudes and Practices of French General Practitioners in a Region of France." International Journal of Obesity, 29 (2005): 1100-1106.

11. Weightlossforall. "Positive Lifestyle Change." 2003. Weightlossforall. 20 Apr. 2009. <http://www.weightlossforall.com/lifestyle_changes.htm>.

12. Zuckerman, M., and Allison, S.N. "An Objective Measure of Fear of Success: Construction and Validation.” Journal of Personality Assessment, 40 (1976): 422-431.

13. The Endocrine Society. "Understanding Obesity." 2009. The Endocrine Society. 20 Apr. 2009. <http://obesityinamerica.org/understandingObesity/index.cfm>. 
NOTES 